\title{
Development and validation of a stability-indicating RP-HPLC method of cholecalciferol in bulk and pharmaceutical formulations: Analytical quality by design approach
}

\author{
Dilipkumar Suryawanshi*, Durgesh Kumar Jha, Umesh Shinde, Purnima D. Amin \\ Department of Pharmaceutical Sciences and Technology, Institute of Chemical Technology, UGC-CAS (Elite Status), Mumbai, India.
}

\begin{tabular}{l}
\hline ARTICLE INFO \\
\hline Received on: 06/11/2018 \\
Accepted on: 06/03/2019 \\
Available online: 05/06/2019 \\
\\
\hline Key words: \\
Cholecalciferol, analytical \\
quality by design, Taguchi \\
orthogonal array design, \\
Box-Behnken design, method \\
validation, forced degradation \\
studies.
\end{tabular}

\begin{abstract}
The present article utilized analytical quality by design (AQbD) methodology to optimize chromatographic conditions for the routine analysis of Cholecalciferol (CHL). Taguchi orthogonal array design and Box-Behnken design were employed to screen and optimize critical method parameters for augmenting the method performance. The optimal chromatographic separation was attained on Eurosphere ${ }^{\circledR} 100-5$, C8 $(250 \times 4.6 \mathrm{~mm}$ i.d., $5 \mu \mathrm{m})$ column in an isocratic elution mode using methanol:acetonitrile (50:50,\% v/v) as mobile phase at a flow rate of $1.0 \mathrm{ml} / \mathrm{minutes}$ and photodiode array detection at $265 \mathrm{~nm}$. The optimized chromatographic method was successfully validated as per International Council for Harmonisation Q2 $\left(R_{1}\right)$ guidelines. The method was found to be linear $\left(r^{2}=0.9993\right)$ in the range of 20-100 IU/ml. Limit of detection and limit of quantitation were found to be 10 and $20 \mathrm{IU} / \mathrm{ml}$. The precision, robustness, and ruggedness values were within the acceptance limits (relative standard deviation $<2$ ). The percent recovery of in-house developed $400 \mathrm{IU}$ mouth dissolving tablets and marketed Tayo 60k tablets were found to be $99.89 \%$ and $101.46 \%$, respectively. The forced degradation products were well resolved from the main peak suggesting the stability-indicating the power of the method. In conclusion, the AQbD-driven method is highly suitable for analysis of CHL in bulk and pharmaceutical formulations.
\end{abstract}

\section{INTRODUCTION}

During product development, quality assurance of pharmaceutical molecules is a matter of great concern in the pharmaceutical industry. Analytical methods are critical elements in product development due to their roles in assisting with process development and product quality control. Poor analytical methods can lead to inaccurate results, resulting in misleading information that may be detrimental to the drug development program. In an endeavor to address such plausible crucial issues, different Pharma regulatory agencies, such as International Council for Harmonisation (ICH) and U.S. Food and Drug Administration, have been transforming by adopting quality by design $(\mathrm{QbD})$

\section{"Corresponding Author}

Dilipkumar Suryawanshi, Department of Pharmaceutical Sciences and Technology, Institute of Chemical Technology, UGC-CAS (Elite Status), Mumbai, India.E-mail: dilipraj14@gmail.com principles to circumvent these quality crises. Recently, ICH has announced new guideline ICH Q14 on analytical procedure development and revision of Q2 $\left(R_{1}\right)$ analytical Validation Q2 $\left(R_{2}\right) / \mathrm{Q} 14$ (ICH Assembly, Kobe, Japan, June 2018).

The traditional liquid chromatographic method development for any drug molecule was performed by a trial and error approach, for example, by varying one-factor-at-a-time and examines the resolution of the result until the best method was found. It is a time-consuming process and required a large amount of manual data interpretation. This approach requires typically some experimental trials, and in some circumstances, the established method requires further modification in method or a supplementary purification stage when scaled up, consequently slackening the drug development process (Monks et al., 2011; Peraman et al., 2015). Moreover, this type of method development provides a limited understanding of a method's capabilities and robustness. This can be overcome by applying QbD principles to the analytical method development as it uses a statistical experimental design to 


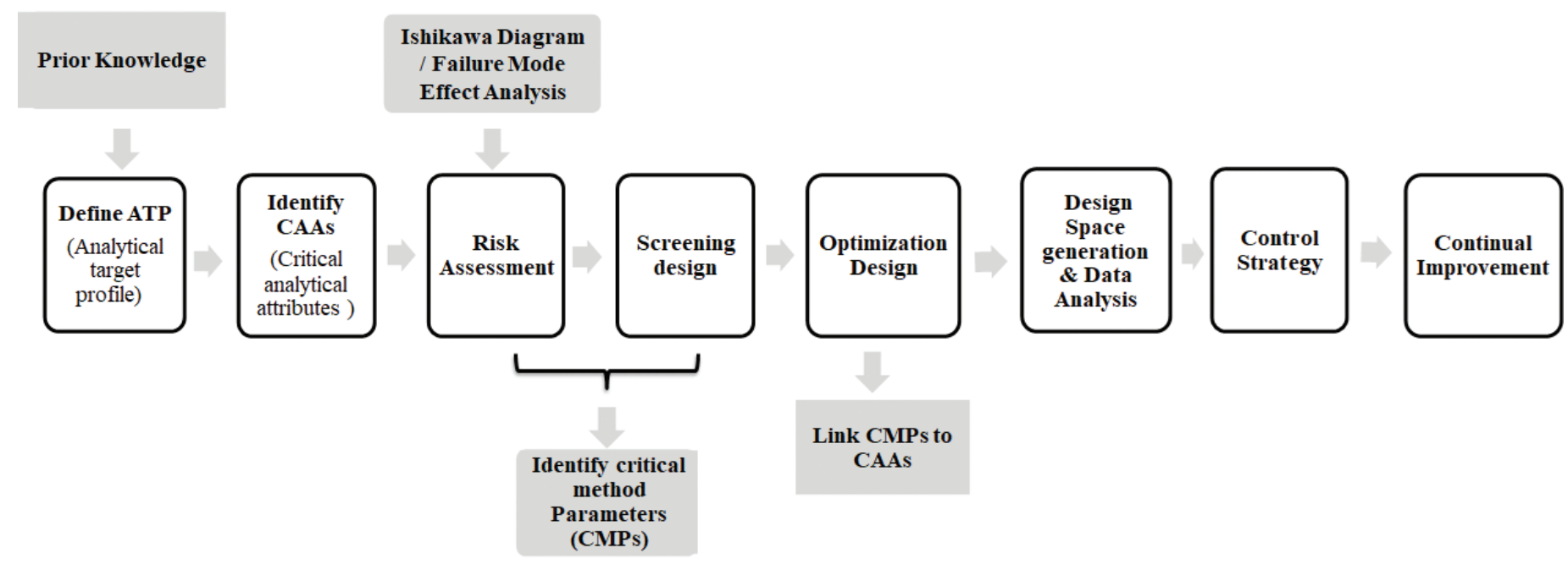

Figure 1. A complete flow layout of $A Q b D$ scheme.

generate a "method operable design space" of a robust analytical method (Peraman et al., 2015). The method operable design space outlines the experimental operable region in which variations to method parameters will not considerably influence the quality and results of the method. Therefore, it will be technically essential to understand if a method operable design space for variations in highperformance liquid chromatography (HPLC) method parameters can be obtained to assist the development of a robust and rugged analytical method (Rozet et al. 2013). Various research scientists have started to adopt the QbD principles and methodology to chromatographic analysis (Awotwe-Otoo et al., 2012; Bossunia et al., 2017; Garg et al., 2015; Ganorkar et al., 2017; Panda et al., 2017; Thakur et al., 2017).

Rational and systematic adoption of quality by design (QbD) elements to analytical method development to achieve optimal method performance is termed as analytical QbD (AQbD) (Jayagopal and Shivashankar, 2017; Reid et al., 2013b). This approach guarantees the high quality and reliability of the analytical method and diminishes the risk of failure in the validation phase and routine practice. It is a scientific and riskbased approach for the understanding of the critical analytical attributes (CAAs) and influential independent factors impacting the method performance. Instituted on the doctrines of risks assessment and design of experiments, AQbD offers the in-depth knowledge about the possible risks and connected interactions between the method variables (Borman et al., 2010; Jayagopal and Shivashankar, 2017; Karmarkar et al., 2011; Reid et al., 2013a; 2013b). Besides, AQbD helps in reducing and controlling the source of variability to gain in-process information for taking control decisions promptly. Figure 1 portrays a complete flow layout of AQbD scheme.

Cholecalciferol (CHL), renowned as vitamin $\mathrm{D}_{3}$, is the most widely prescribed drug for vitamin $\mathrm{D}_{3}$ deficiency. Vitamin $\mathrm{D}_{3}$ deficiency is associated with osteoporosis and osteomalacia in adults and rickets in children (Holick and Chen, 2008). CHL plays a critical role in calcium and phosphorus homeostasis and skeletal mineralization (Gueli et al., 2012). In common medical practice, vitamin $\mathrm{D}_{3}$ deficiency is normally treated with $\mathrm{CHL}$ ranging from 400 to $1,000 \mathrm{IU} /$ day. Recent studies of the physiologic effects of vitamin $\mathrm{D}_{3}$ suggest its role in autoimmune diseases like cancers, type 1 diabetes mellitus, hypertension, multiple sclerosis, Alzheimer's disease, and cognitive impairment (Marques et al., 2010). Chemically, it is (3ß,5Z, 7E)-9, 10-secocholesta-5,7,10(19)trien-3-ol. CHL exists as a white, odorless needle-like crystalline powder, soluble in ethanol, benzene, acetone, chloroform, and fatty oils but practically insoluble in water. The $\log \mathrm{P}$ of the drug substance is 10.24 at $20^{\circ} \mathrm{C}$ and $\mathrm{pH} 7$. The molecular weight of CHL is $384.64 \mathrm{~g} / \mathrm{mol}$ and formula is $\mathrm{C}_{27} \mathrm{H}_{44} \mathrm{O}$. Figure 2 depicts the chemical structure of the CHL.

The USP analytical method is the only reliable method for CHL estimation, but suffers from various disadvantages of having complicated, tedious, multiple extraction steps that make it as time-consuming method. Also, the majority of published HPLC-UV methods of vitamin $\mathrm{D}_{3}$ have limited application as they have complex mobile phase composition, no stability indicating capability, longer retention time, i.e., more than 10 minutes and mostly followed by time consuming and complicated sample

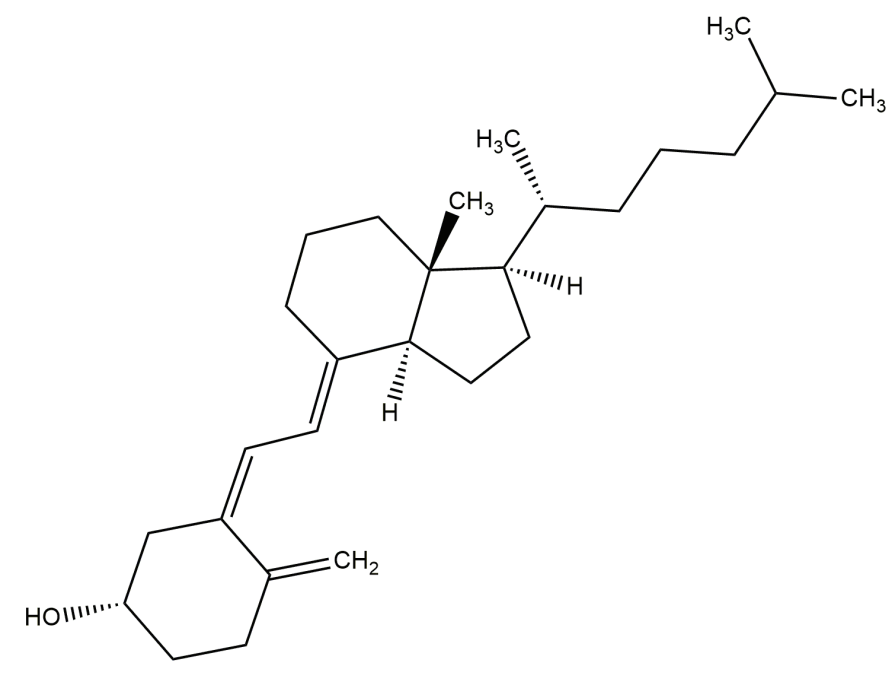

Figure 2. Chemical structure of Cholecalciferol. 
preparation for instance solid phase extraction or supercritical fluid extraction (Al-Qadi et al., 2010; Gamiz-Gracia et al., 2000; Kienen et al., 2008; Klejdus et al., 2004; Kucukkolbasti et al., 2013; Luque-Garcia and de Castro, 2001; Moreno and Salvado, 2000; Sarioglu et al., 2001). Moreover, scientific and risk-based AQbD-oriented approach to reversed-phase HPLC (RP-HPLC) method development of CHL has not been widely discussed till date. Therefore, there is an unmet need for the development of robust, simple, and highly sensitive HPLC method of CHL using $\mathrm{AQbD}$ principles to overcome the problems as mentioned above and to ensure the quality of the method throughout the material lifecycle.

In this research article, the ultimate goal of present work was to develop simple, rapid, sensitive, robust, effective, and reliable stability-indicating HPLC method by applying AQbD principles and methodology for assessment of CHL in bulk drug and pharmaceutical drug products, i.e., CHL 400 IU mouth dissolving tablets and marketed $60000 \mathrm{IU}$ chewable (Tayo 60k) tablets.

\section{MATERIALS AND METHODS}

\section{Experimental}

\section{Chemicals and reagents}

CHL (purity 99.7\%, 40,000 IU/mg) was obtained as a gift sample from Fermenta Biotech Ltd, Mumbai, India; used as a reference standard. HPLC grade acetonitrile (ACN) and methanol $(\mathrm{MeOH})$ were purchased from Avantor Performance Materials India Ltd, Thane, India. The mobile phase was filtered using 0.45- $\mu \mathrm{m}$ nylon membrane filters made by Pall India Pvt Ltd, Mumbai, India, was sonicated, and degassed using sonicator. Inhouse $400 \mathrm{IU}$ vitamin $\mathrm{D}_{3}$ mouth dissolving tablets (MDTs) and marketed cholecalciferol 60,000 IU chewable tablets (Tayo 60k manufactured by Eris Lifesciences Pvt. Ltd.) were analyzed for assay by use of the established RP-HPLC method.

\section{Instrumentation and chromatographic conditions}

The HPLC method development of CHL was performed on Jasco AS-2055 plus (Tokyo, Japan) containing a system controller, quaternary gradient pump, mobile phase degasser, autoinjector (injection volume ranging between 5 and $100 \mu \mathrm{l}$ ) and photodiode array (PDA) detector. Chromatographic separation was achieved on a reversed-phase C8 column, Eurosphere ${ }^{\circledR} 100$ 5 C8 (M/S KNAUER Wissenschaftliche Gerate GmbH, Berlin, Germany) with a dimension of $250 \mathrm{~mm} \times 4.6 \mathrm{~mm}$ and particle size $5 \mu \mathrm{m}$, at the room temperature. Isocratic elution was employed with $\mathrm{ACN}$ and $\mathrm{MeOH}(50: 50, \% \mathrm{v} / \mathrm{v})$ as mobile phase and PDA detection was carried out at $265 \mathrm{~nm}$. Before the chromatographic analysis of test solutions, the column was saturated with the mobile phase for 60 minutes. The $50 \mu \mathrm{l}$ of sample was injected for the quantification of CHL. The run time of all the test samples was kept 10 minutes. The run time for forced degradation test samples was extended up to 20 minutes to estimate probable co-eluting degradation products. The data acquisition, analysis, and storage were performed by using Jasco ChromNAV software.

\section{Preparation of standard stock solution}

The stock solution of CHL was prepared by dissolving accurately weighed $25 \mathrm{mg}$ of the drug in $50 \mathrm{ml}$ of $\mathrm{MeOH}$. The drug solution was sonicated to dissolve the drug, and then $1 \mathrm{ml}$ of this stock solution transferred into $100 \mathrm{ml}$ of amber colored volumetric flask, and it was diluted up to $100 \mathrm{ml}$ with HPLC grade $\mathrm{MeOH}$ (final concentration, $200 \mathrm{IU} / \mathrm{ml}$, knowing that $1 \mathrm{IU}$ of vitamin $\mathrm{D}_{3}=0.025 \mu \mathrm{g}$ ). It was used for both screening and optimization experiments. The working standard solutions of CHL were prepared by subsequent dilutions of the stock solution. The series of dilutions were done using HPLC grade $\mathrm{MeOH}$ and filtered using a 0.45 syringe filter. Then, these dilutions were transferred to vials before chromatographic analysis.

\section{Defining the method goals, i.e., analytical target profile (ATP)}

The AQbD-based methodology defines and proposes vital elements of ATP for the stepwise, scientific development of the analytical method. The method goals cover a possible summary of the quality features of the analytical method. Table 1 depicts vital elements of ATP framework for obtaining an efficient HPLC method for CHL.

\section{Critical analytical attributes (CAAs)}

To achieve the anticipated ATP, various CAAs were recognized and explored. These are peak area, retention time, theoretical plates, and peak tailing factor.

Table 1. Vital elements of ATP for HPLC method of CHL.

\begin{tabular}{|c|c|c|}
\hline ATP elements & Target & Justification \\
\hline Target Analyte & CHL & $\begin{array}{l}\text { HPLC method development of CHL is needed for drug content analysis in pharmaceutical drug } \\
\text { products and stability samples. }\end{array}$ \\
\hline Chromatographic mode & RP-HPLC & $\begin{array}{l}\text { Commonly, RP-HPLC has the advantage of good retention of the lipophilic drug molecules as } \\
\text { it consists of hydrophobic stationary phase. CHL exhibits high lipophilicity (log P 10.24). Thus, } \\
\text { reverse-phase method would be more accurate and reliable for this purpose. }\end{array}$ \\
\hline Instrument necessity & Quaternary pump & $\begin{array}{l}\text { Quaternary Pump delivers a precise and efficient mixing of solvents of } \\
\text { mobile phase as compared to the binary pump. }\end{array}$ \\
\hline Sample state & Liquid & In RP-HPLC, analyte should be in a liquid state for its miscibility with mobile phase \\
\hline Standard preparation & Standard dilutions of CHL & Standard dilution of the drug is generally prepared in $\mathrm{MeOH}$ for proper separation \\
\hline Sample preparation & Handling, weighing, sampling, admixing with solvents & $\begin{array}{l}\text { Sample preparation is generally carried out by weighing the accurate quantity of CHL, mixing } \\
\text { with Sample solution to get a stock solution, followed by sonication and appropriate dilutions. }\end{array}$ \\
\hline Method application & For assay of CHL & $\begin{array}{l}\text { The method has applicability for assay of } \mathrm{CHL} \text { and its degradation product in bulk drugs and } \\
\text { pharmaceutical drug products. }\end{array}$ \\
\hline
\end{tabular}




\section{Risk assessment studies}

Risk assessment studies were performed to identify the critical method parameters (CMPs), which are high-risk factors and have a critical impact on the CAAs. In the risk assessment plan, Ishikawa fishbone diagram was constructed to identify potential risk factors that may have an effect on method performance and corresponding causes. This could be method factors like extraction method, extraction time, extraction solvent, etc. and instrumental settings such as chromatographic mode, mobile phase ratio, flow rate, injection volume, etc. From this, high-risk method variables were shortlisted based on criticality and impact on the method CAAs and exposed to further analysis by applying suitable screening and experimental optimization design.

\section{Taguchi orthogonal array screening study design}

Taguchi orthogonal array (TOA) design is a multifactorial two-level design that can be applied for identification and control of the main effect independent variables with a minimum number of experiment runs from various suspected independent factors (Dash et al., 2016; Sahu et al., 2017). Therefore, this experimental design was generally employed for identification of independent factors that could be fixed or eliminated in further study.

The TOA design was employed in this study for screening studies to recognize the CMPs censoriously influencing the method CAAs using the following polynomial model as shown in the following equation:

$$
\begin{aligned}
Y= & A_{0}+A_{1} X_{1}+A_{2} X_{2}+A_{3} X_{3}+A_{4} X_{4} \\
& +A_{5} X_{5}+A_{6} X_{6}+A_{7} X_{7}
\end{aligned}
$$

where, $Y$ is the response variable, $A_{0}$ is the constant, and $A_{1}, A_{2}, A_{3}, A_{4}, A_{5}, A_{6}$ and $A_{7}$ are the regression coefficients of the independent factors.

Table 2 represents the TOA design layout enlisting the different factors with respective low $(-1)$ and high levels $(+1)$ and their studied responses (theoretical plates and peak tailing factor). Standard Pareto charts were drawn to illustrate the effect of each independent factor on the specified responses. Then, the critical factors were recognized and further employed for Box-Behnken design.

\section{Box-Behnken optimization study design}

The optimization of chromatographic conditions was performed by employing three factors, three levels Box-Behnken design to estimate the main, interaction and quadratic effects of critical factors on the specified response variables (Ahmad et al., 2016; Beg et al., 2012; Ferreira et al., 2007; Sahu et al., 2015; 2017; Wani and Patil, 2017). In the present study, the BoxBehnken experimental design, comprising 15 experiment runs with 12 factorial points and three center points, was employed to get design space for attaining the desired ATP. The polynomial quadratic equation is generated by this design as shown in the following equation:

$$
\begin{aligned}
Y= & B_{0}+B_{1} X_{1}+B_{2} X_{2}+B_{3} X_{3}+B_{12} X_{1} X_{2}+B_{23} X_{2} X_{3}+B_{13} X_{1} X_{3} \\
& +B_{11} X_{1}^{2}+B_{22} X_{2}^{2}+B_{33} X_{3}^{2}
\end{aligned}
$$

where $Y$ is the response variable, $B_{0}$ is the constant, and $B_{1}, B_{2}$, and $B_{3}$ are the regression coefficients of the linear terms

\begin{tabular}{|c|c|c|c|c|c|c|c|}
\hline & \multicolumn{3}{|c|}{ Low level $(-1)$} & \multicolumn{4}{|c|}{ High level (+1) } \\
\hline \multicolumn{8}{|l|}{ Independent factors } \\
\hline $\boldsymbol{X}_{1}$ : Mobile Phase ratio $(\% \mathrm{v} / \mathrm{v})$ & \multicolumn{3}{|c|}{$40: 60$} & \multicolumn{4}{|c|}{$60: 40$} \\
\hline $\boldsymbol{X}_{2}$ : Flow rate (ml/minutes) & \multicolumn{3}{|c|}{0.8} & \multicolumn{4}{|c|}{1.2} \\
\hline $\boldsymbol{X}_{3}$ : Injection volume $(\mu \mathrm{l})$ & \multicolumn{3}{|c|}{10} & \multicolumn{4}{|c|}{30} \\
\hline $\boldsymbol{X}_{4}$ : Mode of Flow & \multicolumn{3}{|c|}{ Isocratic } & \multicolumn{4}{|c|}{ Gradient } \\
\hline $\boldsymbol{X}_{5}:$ Column type & \multicolumn{3}{|c|}{$\mathrm{C}_{8}$} & \multicolumn{4}{|c|}{$\mathrm{C}_{18}$} \\
\hline $\boldsymbol{X}_{6}:$ Column length $(\mathrm{mm})$ & \multicolumn{3}{|c|}{150} & \multicolumn{4}{|c|}{250} \\
\hline $\boldsymbol{X}_{7}$ : Column temperature $\left({ }^{\circ} \mathrm{C}\right)$ & \multicolumn{3}{|c|}{25} & \multicolumn{3}{|c|}{30} & \\
\hline \multicolumn{8}{|l|}{ Dependent factors (responses) } \\
\hline \multicolumn{8}{|l|}{$\boldsymbol{Y}_{1}:$ Theoretical plates } \\
\hline \multicolumn{8}{|l|}{$\boldsymbol{Y}_{2}:$ Peak tailing factor } \\
\hline \multicolumn{8}{|c|}{ Taguchi design layout (seven-factor eight-run) } \\
\hline Runs & $X_{1}$ & $X_{2}$ & $X_{3}$ & $X_{4}$ & $X_{5}$ & $X_{6}$ & $X_{7}$ \\
\hline 1 & -1 & +1 & +1 & +1 & +1 & -1 & -1 \\
\hline 2 & +1 & -1 & +1 & +1 & -1 & +1 & -1 \\
\hline 3 & +1 & -1 & +1 & -1 & +1 & -1 & +1 \\
\hline 4 & -1 & +1 & +1 & -1 & -1 & +1 & +1 \\
\hline 5 & -1 & -1 & -1 & -1 & -1 & -1 & -1 \\
\hline 6 & +1 & +1 & -1 & -1 & +1 & +1 & -1 \\
\hline 7 & -1 & -1 & -1 & +1 & +1 & +1 & +1 \\
\hline 8 & +1 & +1 & -1 & +1 & -1 & -1 & +1 \\
\hline
\end{tabular}
of $X_{1}, X_{2}$, and $X_{3}$, respectively. $B_{12}, B_{23}$ and $B_{13}$ are the regression coefficients for the interaction terms of $X_{1} X_{2}, X_{2} X_{3}$, and $X_{1} X_{3}$,

Table 2. Chromatographic factors and response variables for Taguchi experimental design. 
respectively. $B_{11}, B_{22}$, and $B_{33}$ are the regression coefficients for the squared terms of $X_{12}, X_{22}$, and $X_{32}$, respectively.

The independent variables selected were mobile phase [ACN:MeOH] ratio $\left(X_{1}\right)$, flow rate $\left(X_{2}\right)$, and injection volume $\left(X_{3}\right)$, whereas peak area $\left(Y_{1}\right)$, retention time $\left(Y_{2}\right)$, theoretical plates $\left(Y_{3}\right)$, and peak tailing factor $\left(Y_{4}\right)$ were selected as the dependent responses. The Box-Behnken optimization study design layout is shown in Table 3.

\section{Analytical method validation}

The optimized chromatographic method was validated as per the ICH Q2 $\left(R_{1}\right)$ guidelines for specificity, linearity, accuracy, precision, limit of detection (LOD), limit of quantitation (LOQ), robustness, and ruggedness (Guideline ICH, 2005).

\section{Forced degradation studies}

Forced degradation of CHL was executed to deliver a sign of the stability indicating properties and specificity of the established method (Blessy et al., 2014; Krishna et al., 2016). PDA detection was employed to analyze the purity of degraded test samples. The stress conditions used for the degradation study included acid hydrolysis $(1 \mathrm{~N} \mathrm{HCl})$, base hydrolysis (1 N NaOH), All the test samples were filtered using a $0.45 \mu \mathrm{m}$ nylon membrane filter and analyzed to estimate the percent degradation of CHL.

\section{Application of the analytical method for analysis of CHL in tablet dosage form}

The established and validated analytical method for CHL was applied for its determination in in-house CHL 400 IU mouth dissolving tablets (50\% overages) and marketed 60,000 IU (Tayo $60 \mathrm{k}$ ) chewable tablets. Vitamin $\mathrm{D}_{3}$ MDTs (50\% overages) were manufactured by blending stabilized CHL (100 IU/mg) with other excipients by direct compression technique. To determine the content of CHL in the developed MDTs and marketed chewable tablets, 20 tablets were weighed and finely powdered with the help of mortar and pestle. The required quantity of powder was accurately weighed and transferred to a volumetric flask containing HPLC grade $\mathrm{MeOH}$ and sonicated for 30 minutes, for complete extraction of the drug to take place.Finally, this prepared test sample was filtered through $0.45 \mu$ m nylon membrane before using it for analysis. The analysis was performed in five replicates.

\section{RESULT AND DISCUSSION}

\section{Preliminary method development studies}

The preliminary studies were performed according to previously reported literature for the development of HPLC

Table 3. Chromatographic factors and response variables for Box-Behnken optimization design.

\begin{tabular}{|c|c|c|c|c|}
\hline & & Low level (-1) & Medium level (0) & High level (+1) \\
\hline \multicolumn{5}{|l|}{ Independent factors } \\
\hline $\boldsymbol{X}_{1}$ : Mobile Phase ratio $(\% \mathrm{v} / \mathrm{v})$ & & $40: 60$ & $50: 50$ & $60: 40$ \\
\hline $\boldsymbol{X}_{2}:$ Flow rate (ml/minutes) & & 0.8 & 1.0 & 1.2 \\
\hline $\boldsymbol{X}_{3}$ : Injection volume $(\mu \mathrm{l})$ & & 10 & 20 & 30 \\
\hline \multicolumn{5}{|l|}{ Dependent factors (responses) } \\
\hline \multicolumn{5}{|l|}{$\boldsymbol{Y}_{1}:$ Peak area } \\
\hline \multicolumn{5}{|l|}{$\boldsymbol{Y}_{2}:$ Retention times (minutes) } \\
\hline \multicolumn{5}{|l|}{$\boldsymbol{Y}_{3}:$ Theoretical plates } \\
\hline \multicolumn{5}{|l|}{$\boldsymbol{Y}_{4}$ : Peak tailing factor } \\
\hline \multicolumn{5}{|c|}{ Box-Behnken optimization design layout } \\
\hline Run & Coded level pattern $\left(X_{1} X_{2} X_{3}\right)$ & $\begin{array}{c}X_{1}: \text { Mobile phase } \\
\text { ratio }(\% \mathrm{v} / \mathrm{v})\end{array}$ & $\begin{array}{l}X_{2}: \text { Flow rate } \\
(\mathrm{ml} / \text { minutes })\end{array}$ & $\begin{array}{c}X_{3}: \text { Injection } \\
\text { Volume }(\mu \mathrm{l})\end{array}$ \\
\hline 1 & $0-1+1$ & $50: 50$ & 0.8 & 30 \\
\hline 2 & $+1+10$ & $60: 40$ & 1.2 & 20 \\
\hline 3 & 000 & $50: 50$ & 1 & 20 \\
\hline 4 & $-1+10$ & $40: 60$ & 1.2 & 20 \\
\hline 5 & $-10-1$ & $40: 60$ & 1 & 10 \\
\hline 6 & $+10+1$ & $60: 40$ & 1 & 30 \\
\hline 7 & $-1-10$ & $40: 60$ & 0.8 & 20 \\
\hline 8 & $+1-10$ & $60: 40$ & 0.8 & 20 \\
\hline 9 & 000 & $50: 50$ & 1 & 20 \\
\hline 10 & $+10-1$ & $60: 40$ & 1 & 10 \\
\hline 11 & $0+1+1$ & $50: 50$ & 1.2 & 30 \\
\hline 12 & $-10+1$ & $40: 60$ & 1 & 30 \\
\hline 13 & 000 & $50: 50$ & 1 & 20 \\
\hline 14 & $0-1-1$ & $50: 50$ & 0.8 & 10 \\
\hline 15 & $0+1-1$ & $50: 50$ & 1.2 & 10 \\
\hline
\end{tabular}




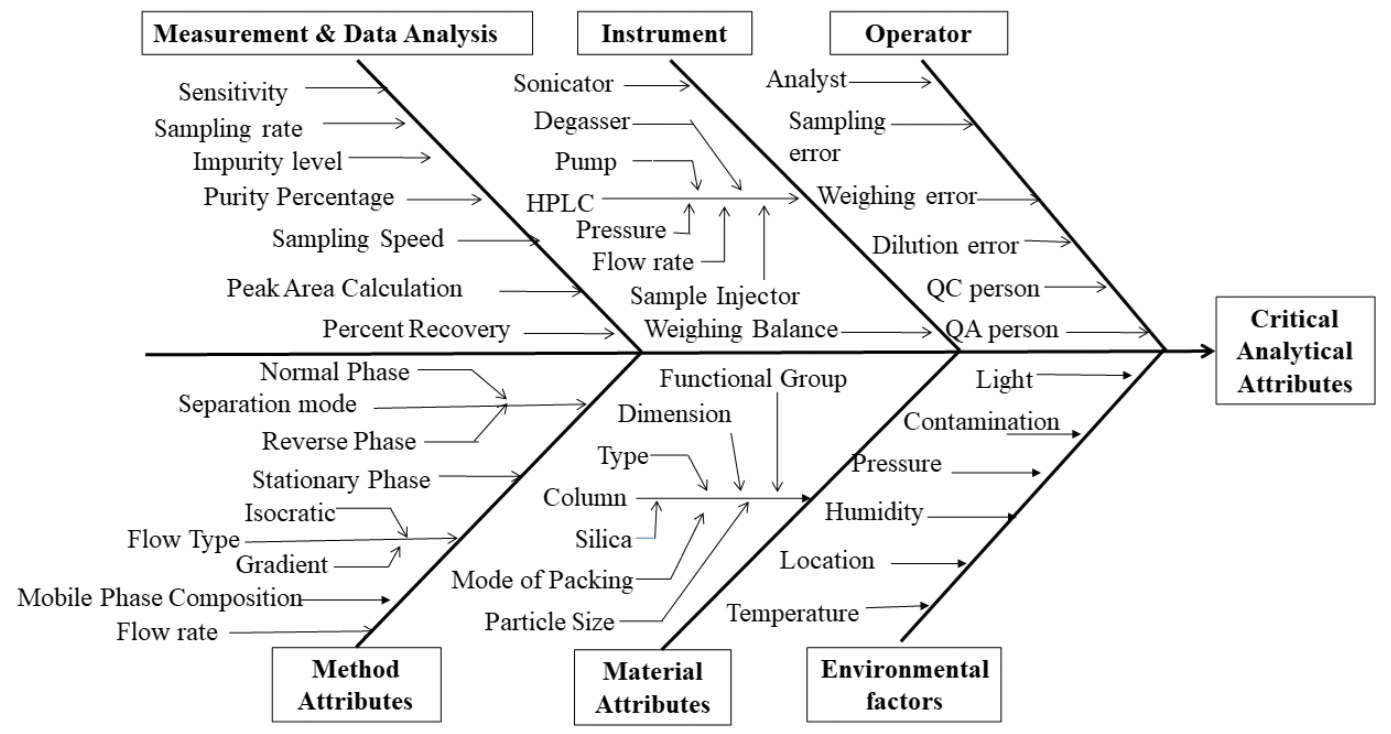

Figure 3. Ishikawa Fish-bone diagram illustrating the influence of possible factors on CAAs of analytical method of CHL.

method for the estimation of CHL in pharmaceutical dosage forms. The RP-HPLC method was successfully employed for evaluation of CHL. First, several combinations of mobile phase were tried by using $\mathrm{ACN}$ and $\mathrm{MeOH}$ at a variable flow rate between 0.8 and $1.2 \mathrm{ml} /$ minutes. From preliminary studies, it was found that the selection of $\mathrm{ACN}$ and $\mathrm{MeOH}$ as a mobile phase composition showed excellent chromatographic resolution with low peak tailing factor.

\section{Risk assessment studies}

Risk assessment studies as per ICH Q9 guidelines were performed with an objective to get all the possible high impact factors which will be subjected to the design of experiment study to establish method operable design region. Ishikawa fishbone was used for risk identification and risk assessment. Figure 3 depicts the effect of possible key factors such as method \& material attributes, environmental factors, operator, instrument requirements, and measurement \& data analysis affecting on method performance. It illustrates the cause and effect relationship between method parameters and CAAs of the analytical method of CHL. Risk assessment studies identified seven high potential risk factors such as $X_{1}$ : mobile phase ratio $(\% \mathrm{v} / \mathrm{v}), X_{2}$ : flow rate (ml/minutes), $X_{3}$ : injection volume $(\mu \mathrm{l}), X_{4}$ : mode of flow, $X_{5}$ : column type, $X_{6}$ : column dimension $(\mathrm{mm})$, and $X_{7}$ : column temperature $\left({ }^{\circ} \mathrm{C}\right)$. These factors have potential impact on critical analytical attributes (CAAs), i.e., theoretical plates $\left(Y_{1}\right)$ and peak tailing factor $\left(Y_{2}\right)$. These seven factors would be used for further screening study to get the major factors affecting selected CAAs by Taguchi orthogonal array (TOA) design.

\section{Taguchi orthogonal array screening study design}

Ideally, screening designs are applied when numerous independent factors expected to have an impact on a specific response. The objective of this study was to identify the most significant factors influencing the CAAs by using TOA screening study design. TOA design was used to estimate the main effects of seven independent factors on selected CAAs. Figure 4 shows the standard Pareto charts illustrating the impact of method parameters on the CAAs of the method. The standard Pareto ranking analysis presented that the factors, such as mobile phase ratio, flow rate, and injection volume, had a significant impact on method CAAs. Hence, these factors were selected as CMPs for further analytical optimization study employing Box-Behnken design.

The standard Pareto charts were derivative of multivariate regression analysis and the length of each bar in the Pareto chart is equal to the magnitude of the regression coefficient of that factor. It was observed that little change in mobile phase ratio, flow rate, and injection volume resulted in a pronounced change in CAAs. Henceforth, these factors needed to be strictly controlled while the effect of mode of flow, column type, column length, and column temperature were found to be statistically insignificant. Based on the desirability function of Taguchi screening design, mobile phase ratio, flow rate, and injection volume were optimized further by Box-Behnken optimization design to detect main, interaction and quadratic effects of these factors on peak area, retention time, theoretical plates, and peak tailing factor.
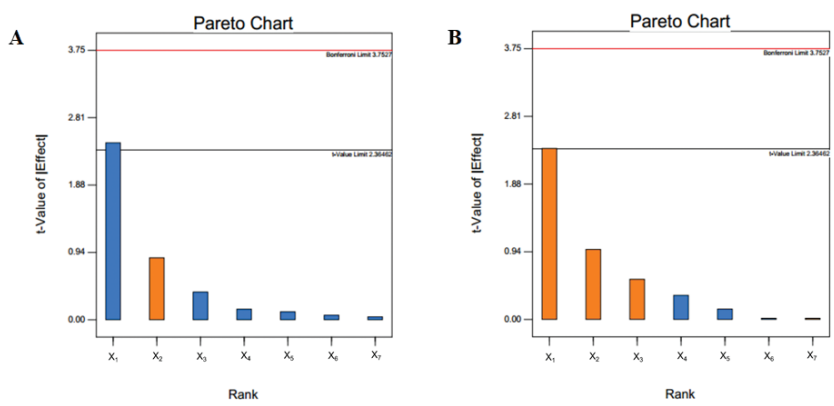

Figure 4. Standard Pareto charts showing effects of independent variables on analytical method CAAs. (A) Theoretical plates and (B) peak tailing factor of CHL during the screening. 


\section{Box-Behnken optimization study design}

This study aimed at detecting the main, interactions and quadratic effects of mobile phase ratio, flow rate, and injection volume on peak area $\left(Y_{1}\right)$, retention time $\left(Y_{2}\right)$, theoretical plates $\left(Y_{3}\right)$, and peak tailing factor $\left(Y_{4}\right)$. The 15 experimental runs were performed, and obtained results were statistically analyzed using Design expert software version 7.0.0 (Stat-Ease Inc., Minneapolis, $\mathrm{MN})$. The software performs response surface methodology, which includes the multiple regression analysis (MRA), analysis of variance (ANOVA), and statistical optimization. The classical polynomial quadratic equation in terms of coded factors for each selected CAAs estimating regression coefficients are shown in the following equations:

$$
\begin{gathered}
\text { Peak area }\left(Y_{1}\right)=11744.33-319.75 X_{1}-14.88 X_{2}+226.88 X_{3}- \\
44.00 X_{1} X_{2}+95.50 X_{2} X_{3}+204.25 X_{1} X_{3}- \\
3260.04 X_{1}^{2}-3059.79 X_{2}^{2}-3375.29 X_{3}^{2} \\
\text { Retention time }\left(Y_{2}\right)=5.03+0.088 X_{1}-0.11 X_{2}+0.025 X_{3}+ \\
0.100 X_{1} X_{2}-0.025 X_{2} X_{3}+0.025 X_{1} X_{3}- \\
0.092 X_{1}^{2}-0.49 X_{2}^{2}-0.32 X_{3}^{2} \\
\text { Theoretical plates }\left(Y_{3}\right)=11442.00+500.12 X_{1}-34.13 X_{+} \\
\\
88.50 X_{3}-50.25 X_{1} X_{2}+124.00 X_{2} X_{3}- \\
\\
70.50 X_{1} X_{3}-2164.13 X_{1}^{2}-1249.62 X_{2}^{2}- \\
1279.38 X_{3}^{2}
\end{gathered}
$$

Peak tailing factor $\left(Y_{4}\right)=1.00-0.094 X_{1}-0.059 X_{2}-0.023 X_{3}+$ $0.045 X_{1} X_{2}+0.052 X_{2} X_{3}+0.052 X_{1} X_{3}+$ $0.22 X_{1}^{2}+0.17 X_{2}^{2}+0.19 X_{3}^{2}$

The ANOVA results for each CAAs were shown in Table 4. The ANOVA with its significance method for all CAAs proves that the relationship between response and variables is statistically significant $(p<0.05)$. The value of correlation coefficient $\left(R^{2}\right)$ for all CAAs indicates a perfect fit of the model. This implies that the model is valid. The adjusted $R$-squared was a more valuable marker of the variation in response variables, while predicted $R$-squared indicated how well the model could predict future data, relatively high values of adjusted and predicted $R$-squared inferred that the applied statistical model effectively predicted the response. The main effects $\left(B_{1}, B_{2}\right.$, and $\left.B_{3}\right)$ signify the average response of varying one factor at a time from its low to high level. The interaction term $\left(B_{12}, B_{23}\right.$, and $\left.B_{13}\right)$ shows how the response changes when two factors are concurrently altered.
The polynomial quadratic terms $\left(B_{11}, B_{22}\right.$, and $\left.B_{33}\right)$ were added to examine nonlinearity. The Polynomial quadratic equations were employed to conclude after considering the magnitude of coefficients and the mathematical sign it carries, i.e., positive or negative.

From Equation (3), it was observed that factors $X_{1}$ and $X_{2}$ have a negative effect, while $X_{3}$ has a positive effect on the peak area. Negative value coefficients of $X_{1}$ and $X_{2}$ factor indicate that peak area increases with a decrease in the mobile phase ratio and flow rate, whereas positive sign of coefficients of $X_{3}$ terms indicates that low to medium level of injection volume favors the increased peak area. When the coefficient values of independent key variables $\left(X_{1}, X_{2}\right.$, and $\left.X_{3}\right)$ compared, the coefficient value of variable $X_{3}$ (226.88) was found to be higher, and hence injection volume was considered to be a major contributing factor for incredible effect on peak area $\left(Y_{1}\right)$.

From Equation (4), variation in mobile phase ratio significantly affects the retention time as the coefficient value of $X_{1}$ was found to be maximum among all independent factors. The polynomial equation for retention time suggests that factor $X_{1}$ has a positive effect on $Y_{2}$, up to a particular concentration. After a particular concentration factor, $X_{1}$ has a negative effect on $Y_{2}$ as indicated by the negative sign of the coefficient of $X_{1}$.

Equation (5) showed that the positive value of coefficients of $X_{1}$ and $X_{3}$ factor indicates that theoretical plates increase with the increase in the mobile phase ratio and injection volume up to medium level. After a medium level factor, $X_{1}$ and $X_{3}$ have a negative effect on $Y_{3}$ as indicated by the negative sign of the coefficient of $X_{1}$ and $X_{3}$. Mobile phase ratio was considered to be an influential factor to have a major impact on theoretical plates as the coefficient value of variable $\mathrm{X}_{1}$ was found to be higher.

From Equation (6), it was observed that the negative sign of coefficients of $X_{1} X_{2}$, and $X_{3}$ terms indicates that low to medium level of independent factors favors the lesser tailing factor. From medium to high level of factors displays increased peak tailing factor. As compared to the magnitude of all factor coefficients, injection volume showed the influential impact on peak tailing factor, while the flow rate was found to have relatively less impact on the peak tailing factor. Minimum values were observed at the intermediate level.

Table 4. ANOVA results for each CAAs.

\begin{tabular}{lcccc}
\hline ANOVA Parameters & $\boldsymbol{Y}_{\mathbf{1}}$ : Peak area & $\boldsymbol{Y}_{\mathbf{2}}$ : Retention time & $\boldsymbol{Y}_{\mathbf{3}}$ : Theoretical plates & $\boldsymbol{Y}_{\mathbf{4}}:$ Peak tailing factor \\
\hline $\boldsymbol{R}$-squared & 0.9965 & 0.9728 & 0.9698 & 0.9588 \\
Adjusted $\boldsymbol{R}$-squared & 0.9901 & 0.9237 & 0.9156 & 0.9145 \\
Predicted $\boldsymbol{R}$-squared & 0.9541 & 0.8978 & 0.8855 & 0.8986 \\
Standard deviation & 268.63 & 0.089 & 415.93 & 0.065 \\
C.V.\% & 4.09 & 1.94 & 4.65 & 4.97 \\
PRESS & $4.697 \mathrm{E}+006$ & 0.54 & $7.301 \mathrm{E}+006$ & 0.33 \\
$\boldsymbol{F}$-value & 156.92 & 19.83 & 17.87 & 12.92 \\
$\boldsymbol{p}$-value & $<0.0001$ & 0.0021 & 0.0027 & 0.0058 \\
\hline
\end{tabular}

$R$-squared $=$ Coefficient of determination.

$F$-value $=$ Value on the $\mathrm{F}$ distribution .

$p$-value $=$ Probability of falsely detecting a significant effect.

PRESS $=$ Predicted errors sum of squares.

C.V. $\%=$ Percent Coefficients of variance. 
Three-dimensional surface and 2-D contour plots were also analyzed to define design space and to visualize the effect of independent factors and their interactions on the concerned response variables. Since the proposed model has more than two independent factors, one factor was kept constant for each plot. These plots were found to agree with MRA and ANOVA parameters. Figure 5 portrays 3D surface plot, and it's corresponding 2D contour plot depicting the effects of mobile phase ratio, flow rate and injection volume on peak area, retention time, theoretical plates, and peak tailing factor.

\section{Identification for optimum method conditions}

Identification for optimum method conditions was performed by numerical optimization simply by trading off different CAAs to gain anticipated targets, i.e., maximum theoretical plates, peak area, retention time around 5 minutes, and minimum peak tailing factor (about 1.0). Desirability function close to one was selected as the optimum solution. The optimized method conditions were found to be mobile phase ratio of 50:50 $(\% \mathrm{v} / \mathrm{v}) \mathrm{ACN}$ and $\mathrm{MeOH}$, the injection volume of $20 \mu \mathrm{l}$, and flow rate of $1 \mathrm{ml} /$ minutes with the desirability of 0.958 (as shown in Fig. 6). The graphical optimization was found to
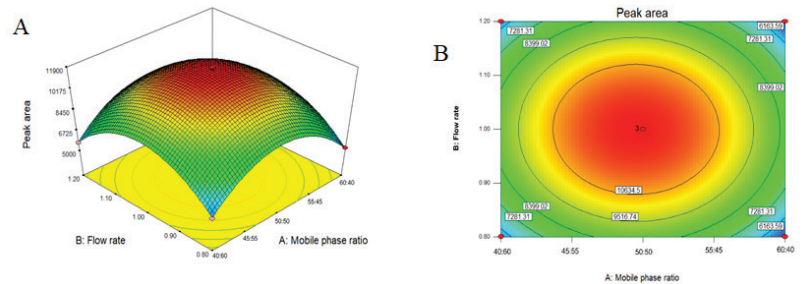

$\mathrm{C}$

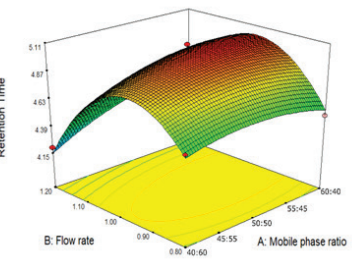

$\mathrm{D}$

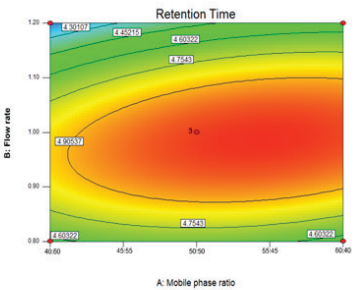

$\mathrm{E}$
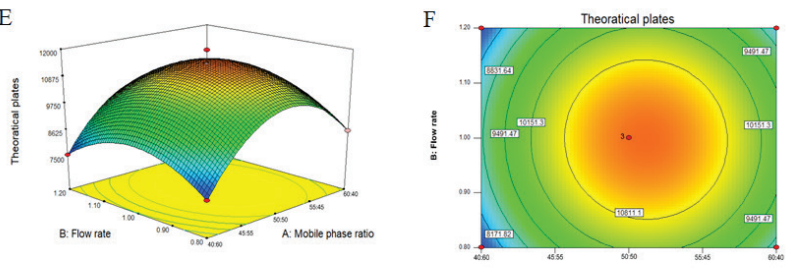

G

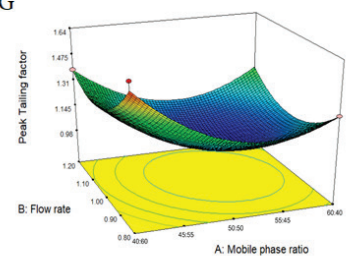

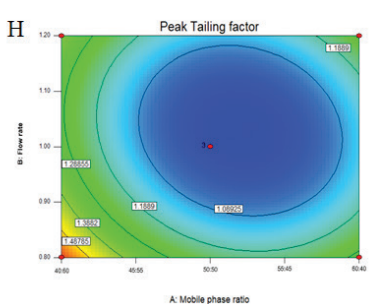

agree numerical optimization and estimated optimized solution was found within operable analytical design space. The yellow region in an overlay plot indicated optimum method conditions suggested by design expert software to obtain method targets as shown in Figure 6.

\section{Analytical method validation}

Figure 7 showed the chromatogram of placebo mixture, standard drug solution, and developed 400 IU MDTs. The placebo does not show any drug peak in the chromatogram. Figure $7 \mathrm{~B}$ shows the standard chromatogram of $40 \mathrm{IU} / \mathrm{ml}$ of CHL with Rt 5.0 minutes. Figure $7 \mathrm{C}$ shows the chromatogram
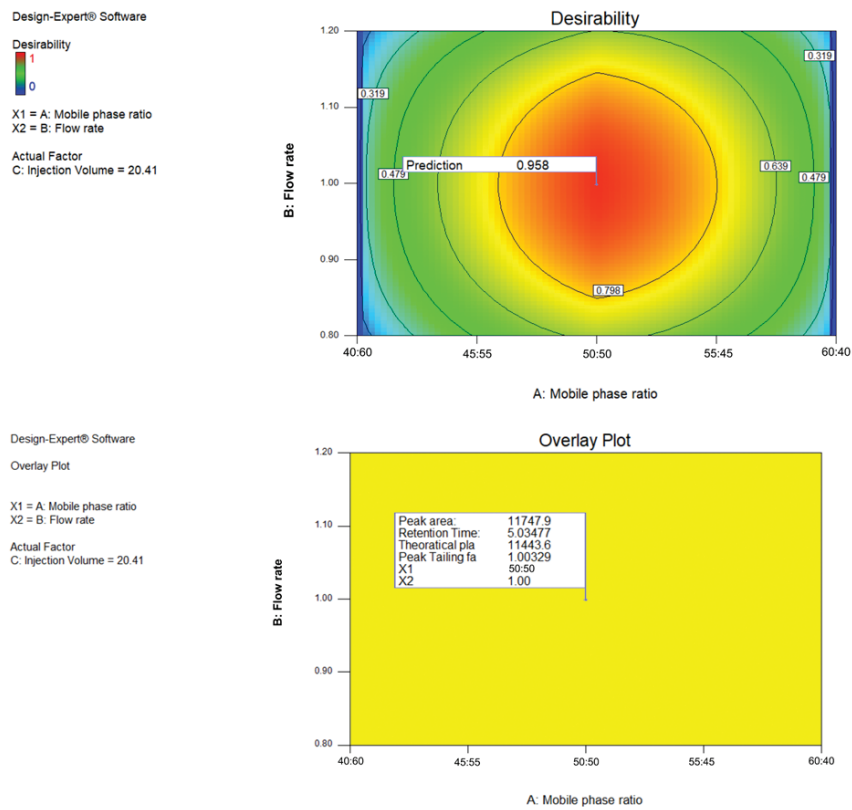

Figure 6. Desirability and overlay contour plot showing optimum method operable design region.
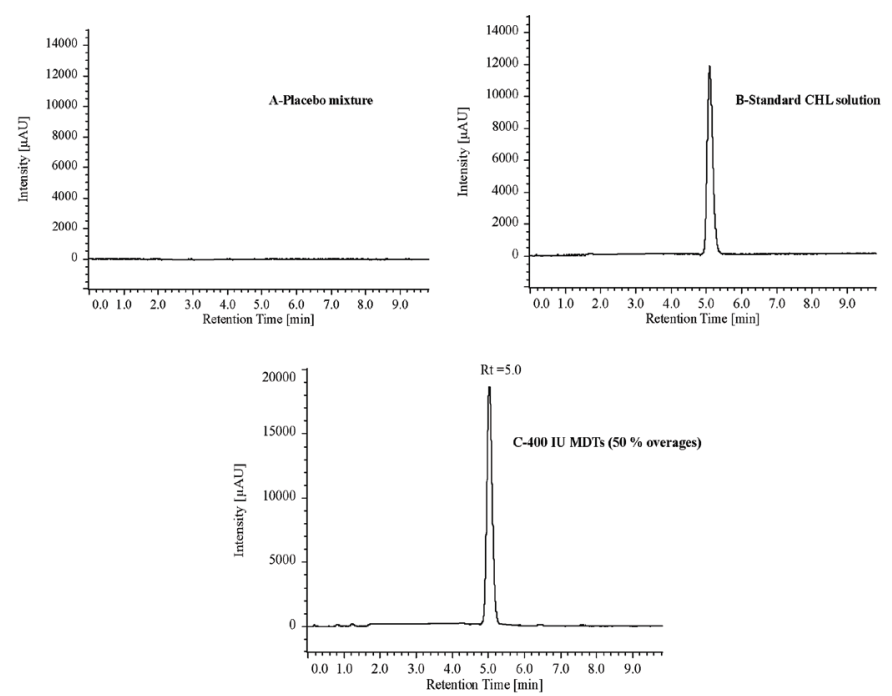

Figure 7. Chromatograms depicting (A) placebo mixture, (B) standard CHL solution, and (C) CHL in the developed formulation, i.e., $400 \mathrm{IU}$ (50\% overages) MDTs.
Figure 5. 3D surface and 2D Contour plots depicting the effect of (A and B) mobile phase ratio and flow rate on peak area, $(\mathrm{C}$ and $\mathrm{D})$ retention time, $(\mathrm{E}$ and F) theoretical plates, and $(\mathrm{G}$ and $\mathrm{H})$ peak tailing factor. 


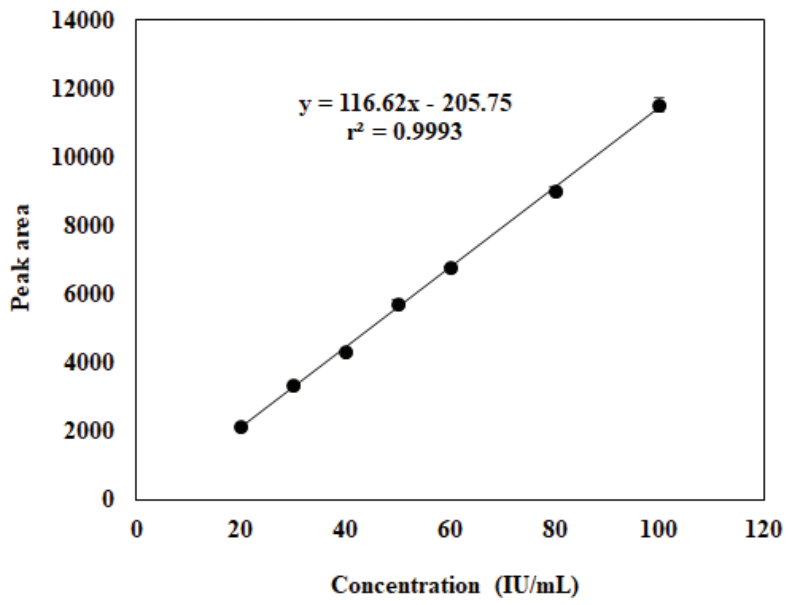

Figure 8. Calibration curve of vitamin $\mathrm{D}_{3}$ in $\mathrm{MeOH}$.

of the drug in a formulation, which confirms no change in the chromatogram of a drug in the presence of other ingredients. There was no interference observed at the retention time of drug peak; thus, method was found to be specific for CHL. Standard calibration curve of CHL in $\mathrm{MeOH}$ was plotted in the range of 20-100 IU/ml (Fig. 8). The method was found to be linear in the selected concentration range with a regression coefficient of 0.9993 .

Data represented in Table 5 summarise the system, intraday and interday precision, solution stability, robustness, and ruggedness of established HPLC method. It can be observed from the table that relative standard deviation \% relative standard deviation (RSD) of each parameter for validation falls within the limit, i.e., not more than $2 \%$.

The LOD and LOQ concentrations were found to be 10 and $20 \mathrm{IU} / \mathrm{ml}$, respectively. The stability of the drug solution of concentration $100 \mathrm{IU} / \mathrm{ml}$ up to 24 hours was estimated by using the established HPLC method. Vitamin $\mathrm{D}_{3}$ was found to be stable in the $\mathrm{MeOH}$. No peaks corresponding to degradation products were observed. The robustness of the projected method was estimated by altering mobile phase composition from Acetonitrile: Methanol 48:52$52: 48 \mathrm{v} / \mathrm{v}$, varying the injection volume from 19.5 to $20.5 \mathrm{ml}$ and changing the flow rate from 0.9 to $1.1 \mathrm{ml} /$ minutes. Acceptable \%RSD values were obtained after making small deliberate changes in the ratio of mobile phase, injection volume, and flow rate. This indicates that the method is robust for the envisioned purpose. The ruggedness of the analytical method by different analysts and different instrument confirms the reliability of the analytical method for ruggedness in the chromatographic conditions.

An excellent recovery with $\% \mathrm{RSD}$ of less than $2 \%$ was obtained from all three levels, i.e., $70 \%, 100 \%$, and $130 \%$. The $\%$ RSD of all the three levels is shown in Table 6. The developed method did not include any pre-treatment, complicated-tedious stages for extraction of CHL. Hence, there was not any recovery problem with this method.
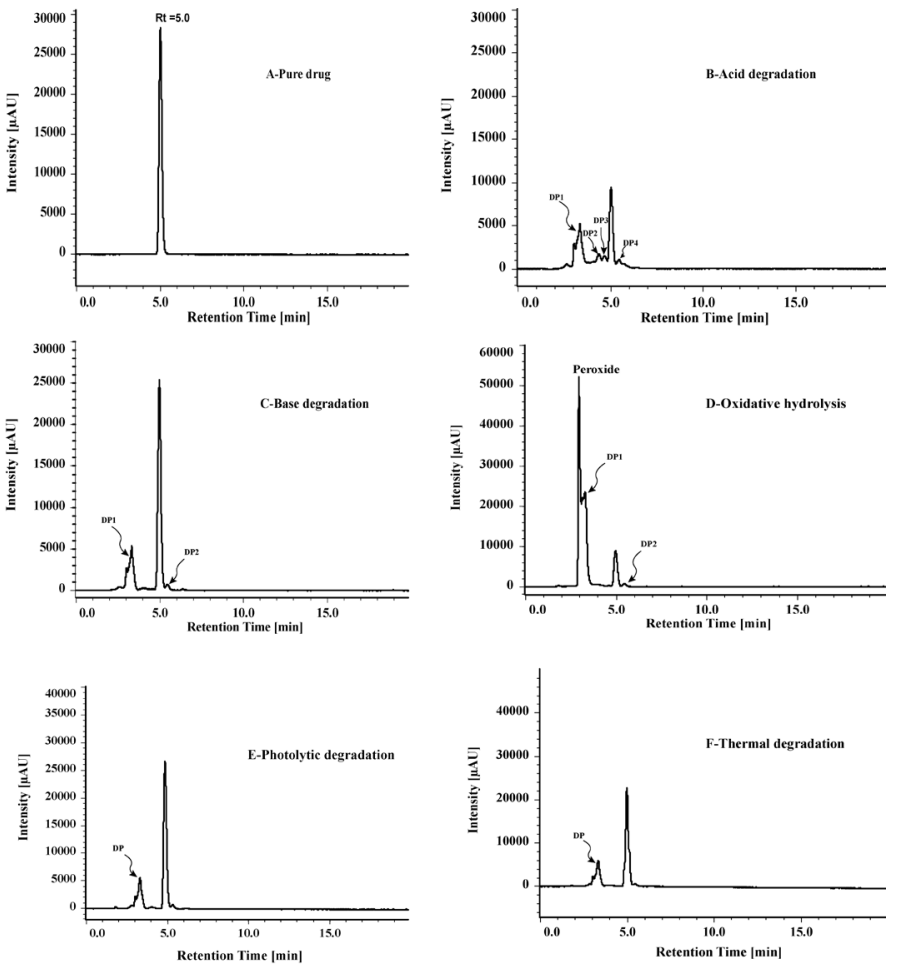

Figure 9. Chromatograms depicting CHL and its DPs under stress conditions (A) Pure drug (B) Acidic (C) Basic (D) Oxidative hydrolysis/Peroxide (E) Photolytic (F) Thermal degradation

\section{Forced degradation studies}

The Forced degradation studies were carried out by analyzing the test samples under all stress conditions and computed the percent degradation of CHL for each stress condition as shown in Table 7. In short, the forced degradation studies revealed that the established method was sensitive enough for the determination of DPs.

\section{Application of the analytical method for analysis of CHL in tablet dosage form}

The chromatographic analysis of 400 IU MDTs and marketed Tayo 60k chewable tablets showed excellent recovery on the assay. The percent recovery of in-house developed 400 IU MDTs and marketed Tayo $60 \mathrm{~K}$ chewable tablets were found to be $99.89 \%$ and $101.46 \%$, respectively. Moreover, the retention time of CHL in tablet formulation showed unchanged with respect to standard CHL solution. Nevertheless, the theoretical factors and peak tailing factor were found to be within the acceptable limits. All test samples showed no unwanted extra peaks in chromatograms that suggested there was no inference of other tablet excipients with CHL. This confirmed a high degree of ability of established method for routine analysis of CHL in bulk and pharmaceutical dosage forms.

\section{Future Research Plan}

The degradation pathway of Cholecalciferol can be further elucidated by using of liquid chromatography-tandem mass spectrometry technique. 


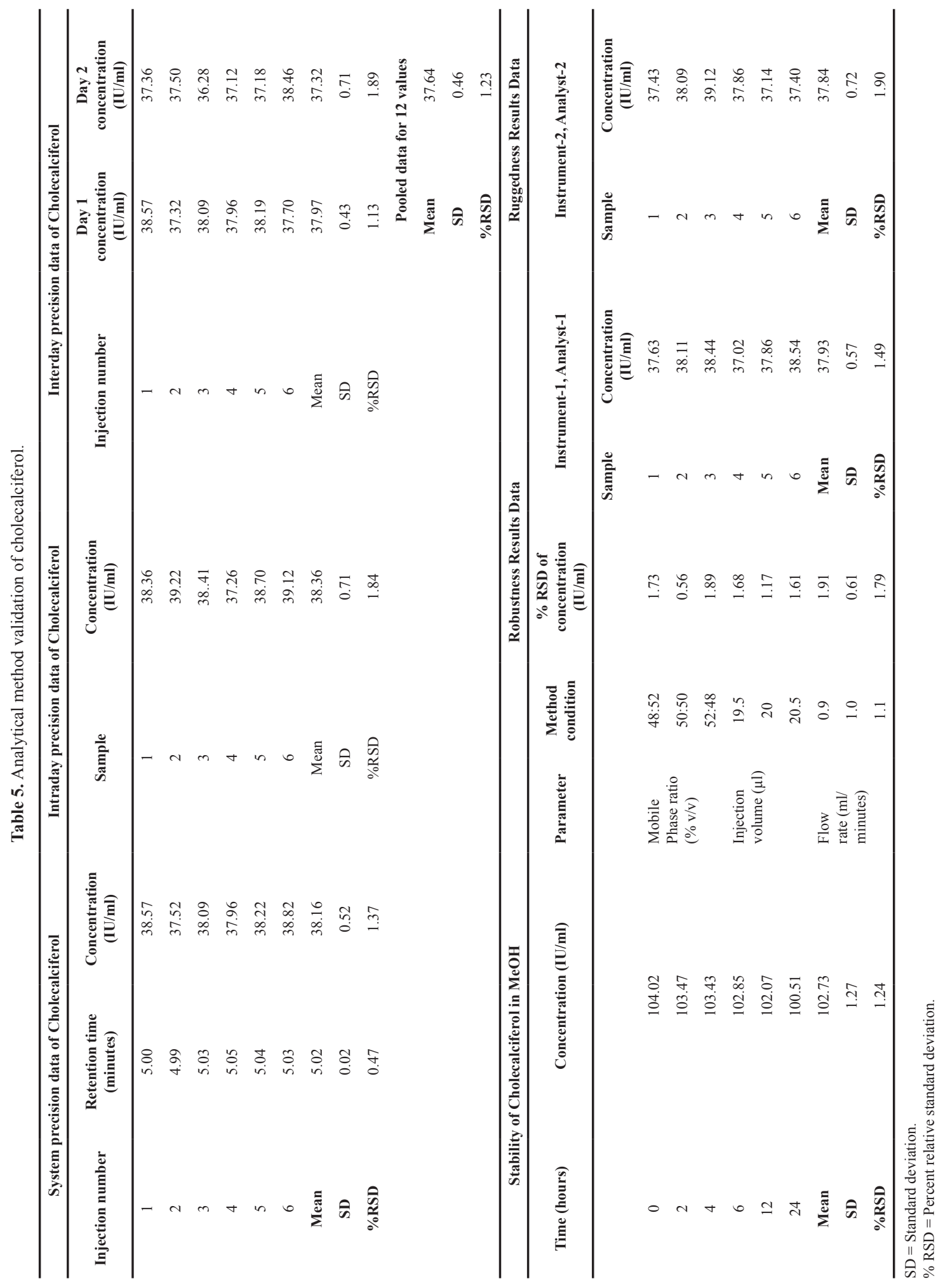


Table 6. Recovery studies of Cholecalciferol formulations.

\begin{tabular}{clccc}
\hline Level & Sample & Recovery (\%) & Mean recovery (\%) & \%RSD \\
\hline $70 \%$ & S1 & 101.09 & 101.80 & 0.92 \\
& S2 & 101.44 & & \\
& S3 & 102.85 & & \\
\multirow{2}{*}{$100 \%$} & S1 & 100.78 & 100.37 & 0.82 \\
& S2 & 99.43 & & \\
& S3 & 100.90 & & \\
$130 \%$ & S1 & 101.24 & 101.05 & \\
& S2 & 101.04 & & \\
& S3 & 100.88 & & \\
\hline
\end{tabular}

$\%$ Recovery $=$ Percent recovery.

$\% \mathrm{RSD}=$ Percent relative standard deviation.

Table 7. Forced degradation studies of Cholecalciferol.

\begin{tabular}{lcl}
\hline $\begin{array}{c}\text { Condition of } \\
\text { degradation }\end{array}$ & $\begin{array}{c}\text { Percentage of } \\
\text { degradation }\end{array}$ & Degradation products retention time (Rt) \\
\hline Acid & $75.12 \%$ & $\begin{array}{l}\mathrm{DP}_{1} \text { at Rt } 3.0, \mathrm{DP}_{2} \text { at Rt } 3.8, \mathrm{DP}_{3} \text { at Rt } 4.7 \text { and } \mathrm{DP}_{4} \\
\text { at Rt } 5.4\end{array}$ \\
Base & $19.32 \%$ & $\mathrm{DP}_{1}$ at Rt 3.0 and $\mathrm{DP}_{2}$ at Rt 5.4 \\
Peroxide & $71.02 \%$ & $\mathrm{DP}_{1}$ at Rt 3.0 and $\mathrm{DP}_{2}$ at Rt 5.4 \\
Thermal & $22.15 \%$ & $\mathrm{DP}_{1}$ at Rt 3.0 \\
Photolytic & $20.82 \%$ & $\mathrm{DP}_{1}$ at Rt 3.0 \\
\hline
\end{tabular}

\section{CONCLUSION}

The present article successfully demonstrates the effectiveness of quality by design concept to optimize the HPLC chromatographic method for CHL analysis with a better understanding of the critical factor-response relationship for augmenting the method performance. This AQbD-driven HPLC method development of CHL ensured robustness of the analytical method before validation studies. This novel approach helps the analyst to define control strategies to decrease the undesirable effect of these CMVs on method performance. The validation studies confirmed excellent linearity, accuracy, precision with a high degree of specificity, sensitivity, robustness, and ruggedness. The forced degradation studies on established HPLC method of CHL easily identified degradation products while exposing to a variety of stress conditions. It was found that CHL was rapidly degraded under oxidative, hydrolytic (acid and alkali), and photolytic conditions. The developed, validated method further used for the analysis of in-house developed vitamin $\mathrm{D}_{3}$ (400 IU) MDTs and marketed chewable tablets Tayo $60 \mathrm{k}(60,000 \mathrm{IU})$ to ratify the applicability of the method. Overall, practicing the AQbD approach for estimation of CHL in tablet dosage form ensured stepwise, scientific, risk-based method development where quality assurance will be guaranteed.

\section{ACKNOWLEDGMENT}

The author would like to thank the University Grants Commission (UGC), New Delhi, India, for providing financial grants to carry out present work as a Research fellow under UGCBSR scheme [No. F.5-63/2007 (BSR) Dated on 16/02/2015]. Authors would also like to thank Merck Specialities Pvt Ltd, Mumbai, India, for providing chemicals and necessary facilities. The authors gratefully acknowledge to Fermenta Biotech Ltd, Mumbai, India, for providing the gift sample of CHL. The author appreciates the vital inputs from Mr. Pradipkumar Wavhule during the compilation of this manuscript.

\section{ABBREVIATIONS}

$\begin{array}{ll}\text { ACN } & \text { Acetonitrile } \\ \text { ANOVA } & \text { Analysis of variance } \\ \text { AQbD } & \text { Analytical quality by design } \\ \text { ATP } & \text { Analytical target profile } \\ \text { BBD } & \text { Box-Behnken design } \\ \text { CAAs } & \text { Critical analytical attributes } \\ \text { CHL } & \text { Cholecalciferol } \\ \text { CMPs } & \text { Critical method parameters } \\ \text { DPs } & \text { Degradation products } \\ \text { ICH } & \text { International Council for } \\ & \text { Harmonization } \\ \text { LC-MS } & \text { Liquid chromatography-tandem mass } \\ & \text { spectrometry } \\ \text { LOD } & \text { Limit of detection } \\ \text { LOQ } & \text { Limit of quantitation } \\ \text { MDTs } & \text { Mouth dissolving tablets } \\ \text { MeOH } & \text { Methanol } \\ \text { MRA } & \text { Multiple regression analysis } \\ \text { PDA } & \text { Photodiode array } \\ \text { RP-HPLC } & \text { Reversed-phase high-performance } \\ & \text { liquid chromatography } \\ \text { RSM } & \text { Response surface methodology } \\ \text { TOA } & \text { Taguchi orthogonal array } \\ \text { USFDA } & \text { United States Food and Drug } \\ & \text { Administration }\end{array}$

\section{CONFLICTS OF INTEREST}

The authors declare that there are no conflicts of interest.

\section{FINANCIAL SUPPORT}

University grants commission (UGC), New Delhi, India, has provided financial grants to carry out present research work. Merck Specialities Pvt Ltd, Mumbai, India, has provided the chemicals and necessary facilities for production of in-house $400 \mathrm{IU}$ MDTs.

\section{REFERENCES}

Ahmad A, Raish M, Alkharfy KM, Mohsin K, Shakeel F. Box-Behnken supported development and validation of robust RP-HPLC method: an application in estimation of pravastatin in bulk and pharmaceutical dosage form. J Chil Chem Soc, 2016; 61:2963-7.

Al-Qadi E, Battah A, Hadidi K. Development of highperformance liquid chromatographic method for vitamin D3 analysis in pharmaceutical preparation. Jordan J Pharm Sci, 2010; 3:78-86.

Awotwe-Otoo D, Agarabi C, Faustino PJ, Habib MJ, Lee S, Khan MA, Shah RB. Application of quality by design elements for the development and optimization of an analytical method for protamine sulfate. J Pharm Biomed Anal, 2012; 62:61-7.

Beg S, Kohli K, Swain S, Hasnain MS. Development and validation of RP-HPLC method for quantitation of amoxicillin trihydrate in bulk and pharmaceutical formulations using Box-Behnken experimental design. J Liq Chromatogr Relat Technol, 2012; 35:393-406.

Blessy M, Patel RD, Prajapati PN, Agrawal YK. Development of forced degradation and stability indicating studies of drugs- - a review. J Pharm Anal, 2014; 4:159-65.

Borman P, Roberts J, Jones C, Bale S. The development phase of an LC method using QbD principles. Sep Sci, 2010; 2:2-8.

Bossunia MTI, Urmi KF, Chironjit Kumar S. Quality-by-design approach to stability indicating RP-HPLC analytical method development 
for estimation of Canagliflozin API and its validation. Pharm Methods, 2017; 8(2):92-101.

Dash RN, Mohammed H, Humaira T. An integrated Taguchi and response surface methodological approach for the optimization of an HPLC method to determine glimepiride in a supersaturatable self-nanoemulsifying formulation. Saudi Pharm J, 2016; 24:92-103.

Ferreira SLC, Bruns RE, Ferreira HS, Matos GD, David JM, Brandao GC, da Silva EGP, Portugal LA, dos Reis PS, Souza AS, dos Santos WNL. Box-Behnken design: an alternative for the optimization of analytical methods. Anal Chim Acta, 2007; 597:179-86.

Gamiz-Gracia L, Jiménez-Carmona MM, de Castro MDL. Determination of vitamins D 2 and D 3 in pharmaceuticals by supercriticalfluid extraction and HPLC separation with UV detection. Chromatographia, $2000 ; 51: 428-32$

Ganorkar SB, Dhumal DM, Shirkhedkar AA. Development and validation of simple RP-HPLC-PDA analytical protocol for zileuton assisted with design of experiments for robustness determination. Arab J Chem, 2017; 10:273-82.

Garg NK, Sharma G, Singh B, Nirbhavane P, Katare OP. Quality by design $(\mathrm{QbD})$-based development and optimization of a simple, robust RP-HPLC method for the estimation of methotrexate. J Liq Chromatogr Relat Technol, 2015; 38:1629-37.

Gueli N, Verrusio W, Linguanti A, Maio FD, Martinez A, Marigliano B, Cacciafesta M. Vitamin D: drug of the future. A new therapeutic approach. Arch Gerontol Geriatr, 2012; 54:222-7.

Guideline ICH. Validation of analytical procedures: text and methodology Q2 (R1). International Conference on Harmonization, Geneva, Switzerland, pp 11-12, 2005.

Holick MF, Chen TC. Vitamin D deficiency: a worldwide problem with health consequences. Am J Clin Nutr, 2008; 87:1080S-6S.

ICH Assembly, Kobe, Japan, June. 2018. Available via http:/ www.ich.org/ichnews/press-releases/view/article/ich-assembly-kobejapan-june-2018.html

Jayagopal B, Shivashankar M. Analytical quality by design-a legitimate paradigm for pharmaceutical analytical method development and validation. Mech Mater Sci Eng J, 2017; 9:1-11.

Karmarkar S, Garber R, Genchanok Y, George S, Yang X, Hammond R. Quality by design (QbD) based development of a stability indicating HPLC method for drug and impurities. J Chromatogr Sci, 2011; 49:439-46.

Kienen V, Costa WF, Visentainer JV, Souza NE, Oliveira CC. Development of a green chromatographic method for determination of fatsoluble vitamins in food and pharmaceutical supplement. Talanta, 2008; 75(1):141-6.

Klejdus B, Petrlova J, Potesil D, Adam V, Mikelova R, Vacek J, Kizek R, Kuban V. Simultaneous determination of water-and fat-soluble vitamins in pharmaceutical preparations by high-performance liquid chromatography coupled with diode array detection. Anal Chim Acta, 2004; 520:57-67.

Krishna MV, Dash RN, Reddy BJ, Venugopal P, Sandeep P, Madhavi G. Quality by design (QbD) approach to develop HPLC method for eberconazole nitrate: application oxidative and photolytic degradation kinetics. J Saudi Chem Soc, 2016; 20:S313-22.

Kucukkolbasti S, Ires N, Kara H. Development of method to simultaneous determination of some water and fat soluble vitamins in feeding additives. J Selcuk Univ Nat Appl Sci, 2013; 1:30-47.

Luque-Garcia JL, de Castro MDL. Extraction of fat-soluble vitamins. J Chromatogr A, 2001; 935:3-11.
Marques CD, Dantas AT, Fragoso TS, Duarte AL. The importance of vitamin D levels in autoimmune diseases. Rev Bras Reumatol, 2010; 50:67-80.

Monks KE, Rieger HJ, Molnar I. Expanding the term "Design Space" in high performance liquid chromatography (I). J Pharm Biomed Anal, 2011; 56:874-9.

Moreno P, Salvado V. Determination of eight water-and fatsoluble vitamins in multi-vitamin pharmaceutical formulations by highperformance liquid chromatography. J Chromatogr A, 2000; 870:207-15.

Panda SS, Ravi Kumar Bera VV, Beg S, Mandal O. Analytical Quality by Design (AQbD)-oriented RP-UFLC method for quantification of lansoprazole with superior method robustness. J Liq Chromatogr Relat Technol, 2017; 40:479-85.

Peraman R, Bhadraya K, Padmanabha Reddy Y. Analytical quality by design: a tool for regulatory flexibility and robust analytics. Int J Anal Chem, 2015; 2015:1-9.

Reid GL, Cheng G, Fortin DT, Harwood JW, Morgado JE, Wang J, Xue G. Reversed-phase liquid chromatographic method development in an analytical quality by design framework. J Liq Chromatogr Relat Technol, 2013a; 36:2612-38.

Reid GL, Morgado J, Barnett K, Fortin D. Analytical quality by design (AQbD) in pharmaceutical development. Am Pharm Rev, 2013b; $16(5)$.

Rozet E, Lebrun P, Hubert P, Debrus B, Boulanger B. Design spaces for analytical methods. TrAC Trends Anal Chem, 2013; 42:157-67.

Sahu PK, Ramisetti NR, Cecchi T, Swain S, Patro CS, Panda J. An overview of experimental designs in HPLC method development and validation. J Pharm Biomed Anal, 2018; 147:590-611.

Sahu PK, Swain S, Prasad GVS, Panda J, Murthy YLN. RPHPLC Method for determination of metaxalone using Box-Behnken experimental design. J Appl Biopharm Pharmacokinet, 2015; 2:40-9.

Sarioglu K, Celebi SS, Mutlu M. A rapid method for determination of vitamins D2 and D3 in pharmaceutical preparations by HPLC. J Liq Chromatogr Relat Technol, 2001; 24:973-82.

Thakur D, Kaur A, Sharma S. Application of QbD based approach in method development of RP-HPLC for simultaneous estimation of antidiabetic drugs in pharmaceutical dosage form. J Pharm Investig, 2017; 47:229-39.

Wani YB, Patil DD. An experimental design approach for optimization of spectrophotometric method for estimation of cefixime trihydrate using ninhydrin as derivatizing reagent in bulk and pharmaceutical formulation. J Saudi Chem Soc, 2017; 21:S101-11.

How to cite this article:

Suryawanshi D, Jha DK, Shinde U, Amin PD. Development and validation of a stability-indicating RP-HPLC method of cholecalciferol in bulk and pharmaceutical formulations: Analytical quality by design approach. J Appl Pharm Sci, 2019; 9(06):021-032. 